28. Metcalfe IL, Enhorning G, Possmayer F 1980 Pulmonary surfactant-associated proteins: their role in the expression of surface activity. J Appl Physiol 49:34

29. Michell RH 1975 Inositol phospholipids and cell surface receptor function. Biochim Biophys Acta 415:81

30. Morley C, Robertson B, Lachmann B, Nilsson R, Bangham A 1980 Artificial surfactant and natural surfactnt: comparative study of the effect on premature rabbit lungs. Arch Dis Child 55:758

31. Nixon DA 1968 The concentration of free myo-inositol in the plasma of perfused sheep fetuses. Biol Neonate 12:113

32. Notter RH, Tabak SA, Mavis RD 1980 Surface properties of binary mixtures of some pulmonary surfactant compoents. J Lipid Res 21:10

33. Notter RH, Taubold R, Mavis RD 1982 Hysteresis in saturated phospholipid films and its potential relevance for lung surfactant function in vivo. Exp Lung Res 3:109

34. Obladen M, Popp D, Schöll C, Schwartz H, Jähnig F 1893 Studies on lung surfactant replacement in respiratory distress syndrome. Rapid film formation from binary mixed liposomes. Biochim Biophys Acta 735:215

35. Okano G, Akino T 1979 Variations in the molecular species of lung phosphatidylglycerol. Lipids 14:541

36. Renkonen O 1966 Individual molecular species of phospholipids. III. Molecular species of ox-brain lecithins. Biochim Biophys Acta 125:288

37. Tanaka J, Takei T, Kanazawa Y 1983 Lung surfactants. II. Effects of fatty acids, triacylglycerols and protein on the activity of lung surfactant. Chem Pharm Bull 31:4100

\title{
Postheparin Plasma Lipases and Carnitine in Infants during Parenteral Nutrition
}

\author{
LIISA ROVAMO
}

Children's Hospital and Third Department of Medicine, University of Helsinki, Helsinki, Finland

\begin{abstract}
Lipoprotein lipase is the rate-limiting factor for hydrolyzing triglycerides to glyerol and fatty acids. Carnitine is a cofactor in the transport of long-chain fatty acids through the mitochondrial membrane for oxidation. To assess these determinants of fat utilization during total parenteral nutrition, lipoprotein and hepatic lipase activities and carnitine concentrations of nine newborn infants, operated on because of gastrointestinal anomalies during the first day of life, were measured with specific methods. Total parenteral nutrition was built up in 3 days whereafter the infants received $3 \mathrm{~g} / \mathrm{kg}$ of fat at a constant rate of infusion for $24 \mathrm{~h} /$ day. Lipoprotein lipase activity of postheparin plasma increased from 14 to $35 \mu \mathrm{mol}$ free fatty acids/ml/h during parenteral nutrition whereas hepatic lipase activity remained unchanged at $40 \mu \mathrm{mol}$ free fatty acids $/ \mathrm{ml} / \mathbf{h}$. Serum free carnitine and acylcarnitine levels decreased significantly during parenteral nutrition; urinary excretion of carnitine decreased also. In addition, serum cholesterol and phospholipids increased markedly during parenteral nutrition whereas serum triglycerides, free fatty acids, and blood $\beta$-hydroxybutyrate remained unchanged. Serum apolipoprotein A-I concentrations were unaltered, apolipoprotein A-II underwent a transient increase, and apolipoprotein $B$ increased monotonically during parenteral nutrition. The results suggest that under the present circumstances neither lipoprotein lipase activity nor carnitine resources are rate-limiting for the utilization of fat in newborn infants during total parenteral nutrition. (Pediatr Res 19: 292-296, 1985)
\end{abstract}

\section{Received April 5, 1984; accepted October 24, 1984.}

Requests for reprints should be addressed to Liisa Rovamo, M.D., Children's Hospital, University of Helsinki, 00290 Helsinki 29, Finland.

This research was supported by Foundation for Pediatric Research, Huhtamäki OY Leiras Pharmaceuticals, Hilma and Heikki Hionkanen's Foundation, Foundation of Nutritional Research, the Finnish Academy, Finnish Foundation for Culture, Sigrid Juselius Foundation, and Nordisk Insulinfond.
Lipoprotein lipase is the rate-limiting factor for clearance of fat from the circulation; it hydrolyzes triglycerides of lipoproteins and fat emulsion particles to glycerol and free fatty acids $(4,19)$. Carnitine is essential for facilitated transport of long-chain free fatty acids across the mitochondrial membrane (9).

Lipoprotein lipase in newborn infants is usually estimated by determining postheparin plasma lipolytic activity $(6,8)$. Postheparin plasma, however, contains hepatic lipase too $(14,26)$. The function of hepatic lipase is unsettled $(11,15,16,18,19)$ but its activity in infants is about three times the activity of lipoprotein lipase $(26,27)$. In addition, these two lipases can vary independently $(26,27)$. Hence, postheparin plasma lipolytic activity is an inadequate measure of lipoprotein lipase.

Adults can synthesize the carnitine they need. Therefore, carnitine is not considered an essential nutrient. Newborn infants may not, however, be capable of sufficient carnitine synthesis. Therefore, infants may be dependent on nutritional sources of carnitine, such as milk. Infants receiving carnitine-free total parenteral nutrition are at risk of developing carnitine deficiency characterized by decreased blood concentration and tissue content of carnitine $(2,20,24,28)$. Reduced carnitine intake may impair fatty acid oxidation and diminish ketogenesis after fat infusion; these deficiencies can be corrected with supplementary carnitine $(23,29)$.

To study the role of the principal regulators of fat metabolism in newborn infants lipoprotein lipase and hepatic lipase activities and carnitine concentrations were measured during parenteral nutrition.

\section{PATIENTS AND METHODS}

Patients. The patients were nine newborn infants who required surgical operation and parenteral nutrition because of gastrointestinal tract anomalies (Table 1). Surgery was performed under general anesthesia during the first day of life. For subsequent parenteral nutrition seven infants received central venous catheters and two infants (patients 4 and 5) peripheral venous catheters; none had a continuous heparin infusion. After the opera- 
Table 1. Clinical data of the newborn infants studied

\begin{tabular}{|c|c|c|c|c|c|}
\hline Patient & $\begin{array}{l}\text { Gestational age } \\
\text { (wk) }\end{array}$ & $\begin{array}{l}\text { Birth wt } \\
\text { (g) }\end{array}$ & $\begin{array}{l}\text { Reason for surgical } \\
\text { operation }\end{array}$ & $\begin{array}{l}\text { Duration of total } \\
\text { parenteral nutrition } \\
\text { (days) }\end{array}$ & Outcome \\
\hline 1 & 39 & 3600 & Jejunal atresia & 16 & $\begin{array}{l}\text { Cystic fibrosis diagnosed at } \\
\text { the age of } 4 \mathrm{mo}\end{array}$ \\
\hline 2 & 41 & 2820 & Gastroschisis & 13 & Recovered \\
\hline 3 & 39 & 3800 & Ileal atresia & 8 & Recovered \\
\hline 4 & 37 & 1840 & Omphalocele & 5 & $\begin{array}{l}\text { Truncus arteriosus: died at } \\
\text { the age of } 2 \mathrm{wk}\end{array}$ \\
\hline 6 & 41 & 2810 & Omphalocele & 10 & $\begin{array}{l}\text { Plastic operation at the age } \\
\text { of } 1 \mathrm{yr} \text {, recovered }\end{array}$ \\
\hline 7 & 35 & 2790 & $\begin{array}{l}\text { Midgut volvulus and short } \\
\text { bowel syndrome }\end{array}$ & 160 & $\begin{array}{l}\text { Cholestasis and two epi- } \\
\text { sodes of septacemia: died } \\
\text { at the age of } 5 \mathrm{mo}\end{array}$ \\
\hline 8 & 33 & 2300 & Duodenal atresia & 72 & $\begin{array}{l}\text { Cholestasis and two epi- } \\
\text { sodes of septicemia, re- } \\
\text { covered }\end{array}$ \\
\hline
\end{tabular}

tion the infants were transferred to the intensive care unit and treated in a respirator during the first 2 days of life. Three infants (patients 2, 6, and 8) needed respiratory support for one week because of abdominal distension. Four of the infants needed phototherapy because of hyperbilirubinemia; one of them (patient 5) had blood group incompatibility.

Parenteral nutrition. During the first 2 days of life the infants received $10 \%$ glucose infusion. Parenteral nutrition was started on the 3rd day and built up during 3 days: amino acid and fat infusions were increased by $1 \mathrm{~g} / \mathrm{kg}$ per day. Amino acids were given as $8.9 \%$ crystalline solution (Aminosteril II, Medipolar, Oulu, Finland), and fat as $10 \%$ emulsion of soybean oil (Intralipid, Kabi Vitrum, Sweden). After the build-up all infants received $2.7 \mathrm{~g} / \mathrm{kg}$ of amino acids, and $3 \mathrm{~g} / \mathrm{kg}$ of fat at a constant rate of infusion each $24 \mathrm{~h}$. The rate of glucose infusion was adjusted according to individual tolerance. During the first 3 days of life the amount of nonnitrogen calories (two-thirds from glucose as $10-30 \%$ solution) was about $40 \mathrm{kcal} / \mathrm{kg} / \mathrm{day}$, between the 4th and 9th day $60-70 \mathrm{kcal} / \mathrm{kg} / \mathrm{day}$, and after the 10 th day $80-100 \mathrm{kcal} / \mathrm{kg} / \mathrm{day}$. The total volume of infusion was $100-150$ $\mathrm{ml} / \mathrm{kg} /$ day. In addition, the infants received normal daily allowances (7) of minerals ( $\mathrm{Na}, \mathrm{K}, \mathrm{Ca}, \mathrm{P}, \mathrm{Mg}$ ), trace minerals (Tracefusin, Leiras, Turku, Finland), and vitamins (Soluvit and Vitalipid Infant, KabiVitrum Sweden). On the average, weight gain started at the age of 5 days and was $16 \mathrm{~g} /$ day. Serum ureanitrogen concentration remained below $15 \mathrm{mg} / \mathrm{dl}$ during parenteral nutrition.

Blood and urine samples. During the first 2-3 wk of parenteral nutrition blood samples of 2-3 ml were taken every other day. Later, blood samples were taken once a week. Routine laboratory measures (7) and concentrations of serum triglycerides, cholesterol, apolipoproteins A-I, A-II, and B, phospholipids, free fatty acids, free carnitine and acylcarnitine, and blood $\beta$-hydroxybutyric acid were determined from these samples.

After discontinuation of parenteral nutrition, when the infants had been solely on breast milk for $1 \mathrm{wk}$, blood samples were taken from patients 1-6 for measuring serum cholesterol, phospholipids, apolipoproteins A-I, A-II, and B, and free carnitine and acylcarnitine.

Plasma lipoprotein and hepatic lipase activities and serum insulin were measured once before the beginning of parenteral nutrition with fat emulsion and amino acid solution. The measurement was repeated once between the 4th and 9th day, once between the 10th and 20th day, and later once a month. Each time a blood sample was first taken to measure serum insulin and the basal activities of the lipases. Then a heparin dose of 100 $\mathrm{IU} / \mathrm{kg}$ was given intravenously. Fifteen minutes later a blood sample was taken to measure lipase activities. Fat infusion was discontinued for $2 \mathrm{~h}$ before and after heparin administration.

Urine was collected for $24 \mathrm{~h}$ before the beginning of parenteral nutrition with fat emulsion and amino acid solution. The collection was repeated during the 10th day and thereafter once a month (patients 7 and 8). Total carnitine concentrations were determined from these samples.

Biochemical assays. Serum triglyceride and cholesterol concentrations were measured with an enzymatic method (commercial reagent kit no. 187313 for cholesterol and no. 29771 for triglycerides, Boehringer Diagnostica GmbH, Mannheim, West Germany). Serum phospholipid concentration was measured as inorganic phosphate (1). Serum apolipoprotein A-I, A-II, and B concentrations were measured with a radial immunodiffusion method $(3,5)$. Serum free fatty acid concentration was measured with an enzymatic method (Nefa C-Test, Wako, Wako Pure Chemical Industries LTD, Japan). Blood $\beta$-hydroxybutyric acid concentration was measured with a fluorometric method (21). Serum insulin concentration was measured using radioimmunoassay (commercial kit, Amersham, Bucks, England). Free and total carnitine concentrations were measured with the method of McGarry and Foster (17) modified according to Novak et al. (20) for both serum and tissue. Acylcarnitine was calculated by subtracting free carnitine from total carnitine. Postheparin plasma lipoprotein and hepatic lipase activities were measured with the immunochemical method of Huttunen et al. (14): lipoprotein lipase was measured after inactivating hepatic lipase with a specific antiserum; hepatic lipase was measured at $1 \mathrm{M}$ $\mathrm{NaCl}$ concentration inactivating lipoprotein lipase, no serum was added. The activities are expressed in $\mu \mathrm{mol}$ of free fatty acid released from radioactive triolein substrate per $1 \mathrm{ml}$ of plasma in $1 \mathrm{~h}$.

Statistical analysis. One-way analysis of variance for repeated measures with age group as a within factor was performed under the assumption of normal distribution with P2V of the BMDP statistical software.

The study protocol was approved by the Ethical Committee of the Children's Hospital, University of Helsinki.

\section{RESULTS}

Serum cholesterol (Fig. $1 A$ ) and phospholipid (Fig. $1 B$ ) concentrations increased markedly $(p<0.0001)$ during parenteral nutrition. In contrast, serum triglyceride, free fatty acid, and blood $\beta$-hydroxybutyrate levels (Fig. 2) remained practically unchanged. Only during the first 2 days of parenteral nutrition did two infants have triglyceride concentrations higher than 3.0 

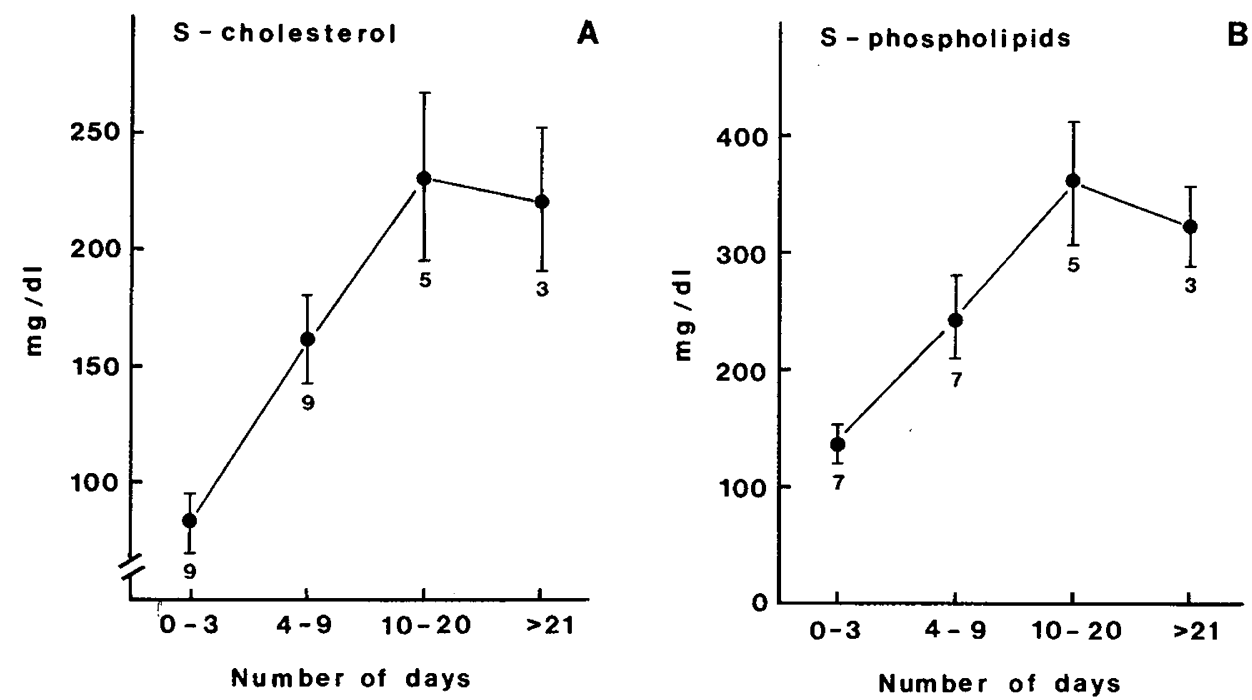

Fig. 1. Serum cholesterol and phospholipid concentrations (mean \pm SEM) of newborn infants during parenteral nutrition. Number of days indicates age and the duration of parenteral nutrition. Numbers close to curves refer to the number of patients.
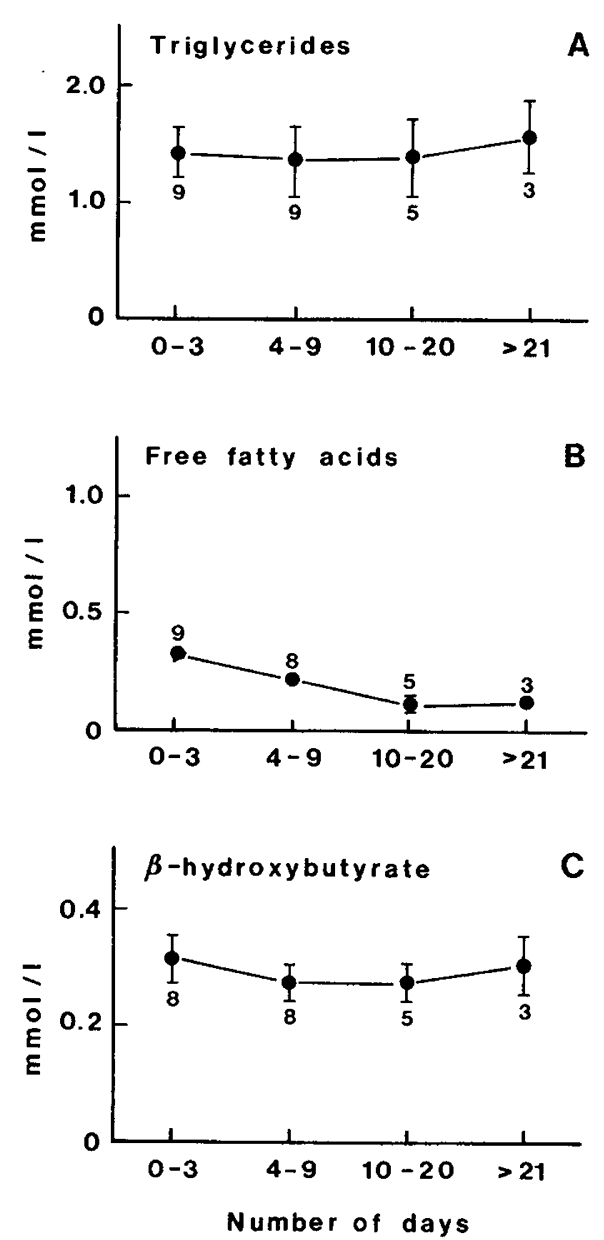

Fig. 2. Serum triglyceride, free fatty acid, and $\beta$-hydroxybutyrate concentrations (mean \pm SEM) of newborn infants during parenteral nutrition. For other details see Figure 1.

$\mathrm{mmol} / \mathrm{liter}$. Hence, the triglycerides infused were eliminated efficiently.

During parenteral nutrition apolipoprotein A-I (Fig. $3 A$ ) remained practically unchanged, apolipoprotein A-II (Fig. $3 B$ ) first increased and then decreased $(p<0.05)$, and apolipoprotein B (Fig. $3 C$ ) increased monotonically $(p<0.05)$.

The mean lipoprotein and hepatic lipase activities (Fig. 4, 0-
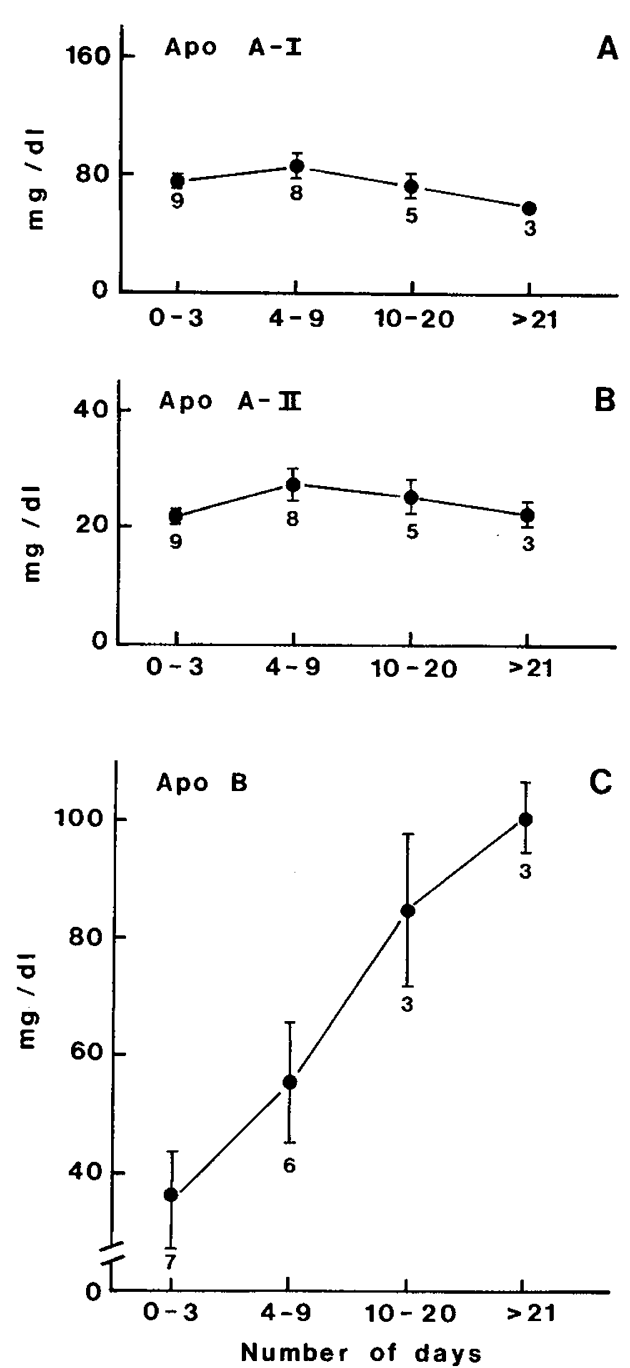

Fig. 3. Serum apolipoprotein A-I, A-II, and B concentrations (mean \pm SEM) of newborn infants during parenteral nutrition. For other details see Figure 1.

3 days) were normal $(25,26)$ before the beginning of the infusion of fat emulsion and amino acids. During parenteral nutrition lipoprotein lipase activity (Fig. $4 A$ ) increased considerably ( $p<$ 0.01 ), whereas hepatic lipase activity (Fig. $4 B$ ) remained con- 

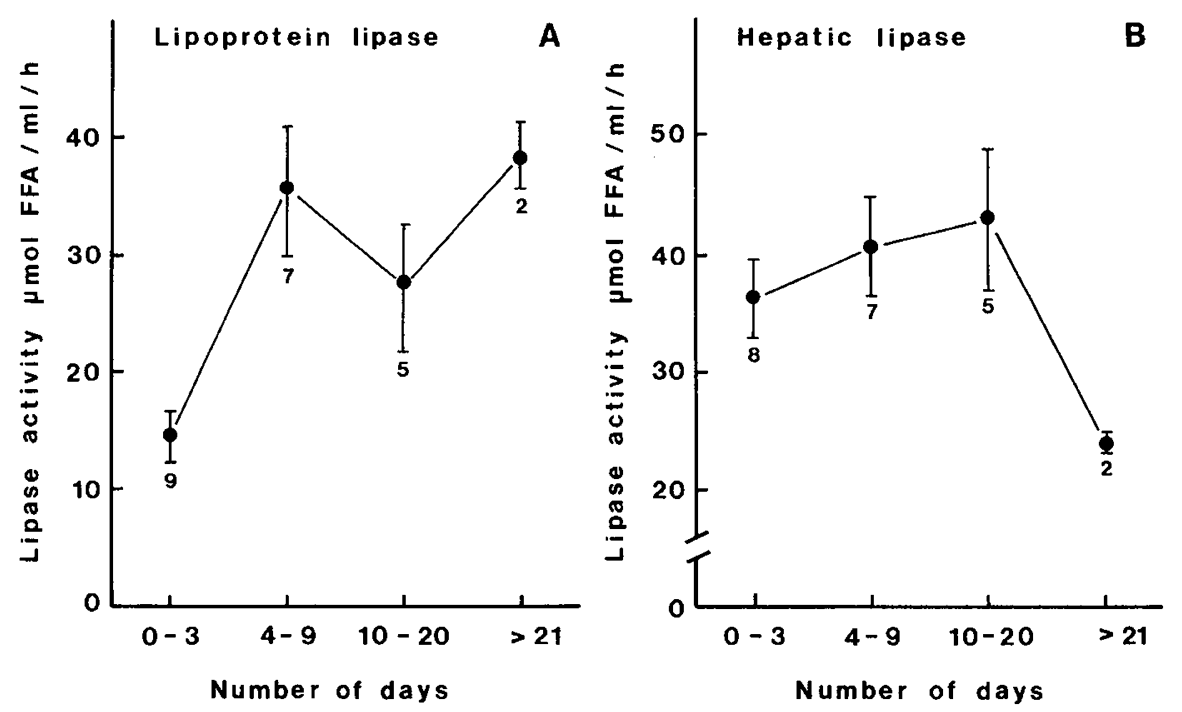

Fig. 4. Postheparin plasma lipoprotein and hepatic lipase activities (mean \pm SEM) of newborn infants during parenteral nutrition. For other details see Figure 1.

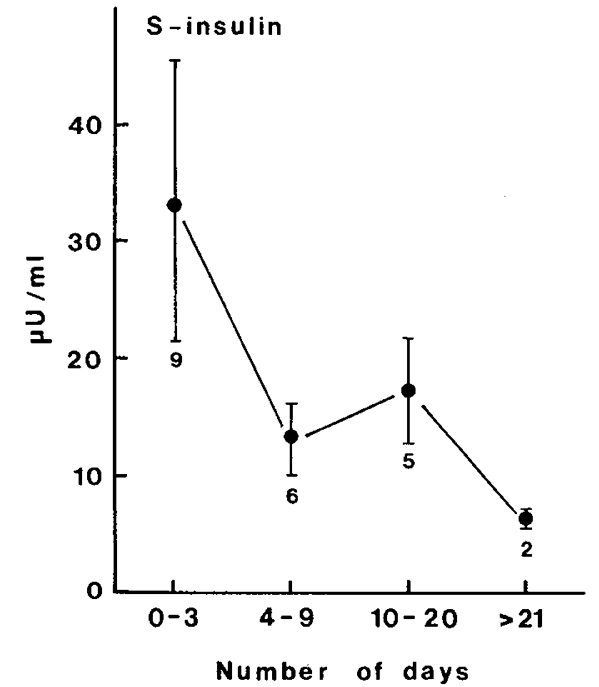

Fig. 5. Serum insulin concentration (mean \pm SEM) of newborn infants during parenteral nutrition. For other details see Figure 1.

stant. However, after 3 wk hepatic lipase activity decreased considerably in the two infants (patients 7 and 8) who were still under parenteral nutrition.

The decrease of serum insulin concentration (Fig. 5) during parenteral nutrition was not statistically significant.

Serum total, free, and acylcarnitine concentrations all decreased significantly $(p<0.01)$ during parenteral nutrition (Fig. 6).

Total carnitine excretion in urine at 0-3 days of age was on the average $114 \mathrm{nmol} / \mathrm{mg}$ of creatinine, and by the age of 10 days it decreased $(p<0.05)$ to $68 \mathrm{nmol} / \mathrm{mg}$ of creatinine.

During parenteral nutrition there was a low (14.5 $\mu \mathrm{mol} / \mathrm{liter})$ serum carnitine concentration and no measurable urinary excretion of carnitine in one infant (patient 7) who died at the age of 5 months. Her total carnitine concentrations in muscle $(27 \mathrm{nmol} /$ $\mathrm{mg}$ of protein or $12 \mathrm{nmol} / \mathrm{mg}$ of dry weight) and heart $(7.2$ $\mathrm{nmol} / \mathrm{mg}$ of protein or $4.9 \mathrm{nmol} / \mathrm{mg}$ of dry weight) were, however, normal when compared with five muscle biopsies from adults $(19 \mathrm{nmol} / \mathrm{mg}$ of protein; SEM 2.0 or $13 \mathrm{nmol} / \mathrm{mg}$ of dry weight; SEM 1.1) and three heart muscle samples $(6.7 \mathrm{nmol} / \mathrm{mg}$ of protein; SEM 1.1 or $3.1 \mathrm{nmol} / \mathrm{mg}$ of dry weight; SEM 1.4) from autopsied infants.

After parenteral nutrition the concentration of cholesterol ( $n$
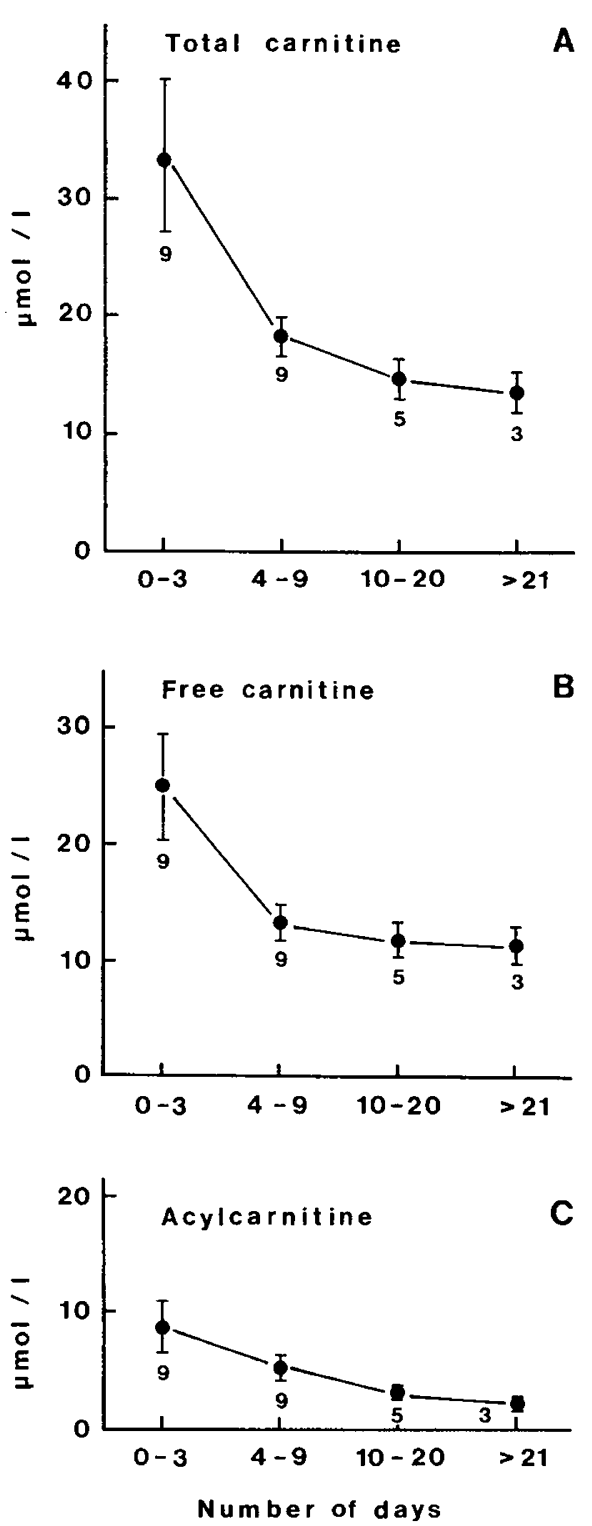

Fig. 6. Serum total, free, and acylcarnitine concentrations (mean \pm SEM) of newborn infants during parenteral nutrition. For other details see Figure 1. 
$=5)$ and apolipoproteins B and A-II $(n=4)$ were as during parenteral nutrition. In contrast, phospholipid level $(n=4)$ decreased $(p<0.05)$ from 300 to $160 \mathrm{mg} / \mathrm{dl}$ and apolipoprotein A-I $(n=4)$ increased $(p<0.05)$ from 77 to $110 \mathrm{mg} / \mathrm{dl}$. Also, serum concentration of free carnitine $(n=4)$ increased $(p<$ 0.05 ) from 10.9 to $20.9 \mu \mathrm{mol} / \mathrm{liter}$, whereas the increases in total carnitine and acylcarnitine were not statistically significant.

\section{DISCUSSION}

In agreement with Griffin et al. (13), it was found that serum cholesterol and phospholipids increased markedly in newborn infants during parenteral nutrition, which may result from fat emulsion infusion.

Apolipoprotein concentrations have not been measured previously in newborn infants during parenteral nutrition. I found that the concentration of apolipoprotein A-I remained constant, apolipoprotein A-II first increased and then decreased, and apolipoprotein B increased monotonically with age. Hence, during short-term parenteral nutrition apolipoproteins A-I and A-II seem to behave as in adults (30). The increase of apolipoprotein B may result, at least partially, from the increase of cholesterol and phospholipids that occurs in low density lipoproteins (13) because apolipoprotein B is the major protein moiety of low density lipoproteins. In breast-fed newborn infants the concentrations of apolipoproteins A-I, A-II, and B increase progressively with postnatal age (31). These apolipoproteins are in part synthesized in the intestine (12), which might explain why these apolipoproteins do not behave similarly during breast-feeding and parenteral nutrition.

Lipoprotein lipase activity has not been previously measured during parenteral nutrition in infants. I found that plasma lipoprotein lipase activity increased considerably during parenteral nutrition. This accounts for the increase of postheparin lipolytic activity that occurs in infants during parenteral nutrition (8). Also, lipoprotein lipase activity of adipose tissue has been shown to increase during parenteral nutrition in adults $(30)$. The increase of lipoprotein lipase activity observed may relate to increasing daily caloric intake (8). However, in the present study the increase of lipase activity leveled off before caloric intake reached a steady state. On the other hand, it has been proposed that fat infusion induces lipoprotein lipase activity $(8,30)$. In agreement, the increase of lipoprotein lipase activity coincided with the beginning of fat infusion. Moreover, insulin is a known inducer of lipoprotein lipase (10). However, basal insulin concentrations, in contrast to lipoprotein lipase, did not increase during parenteral nutrition.

Triglyceride levels were high only occasionally during the first days of parenteral nutrition. Similarly, preterm infants younger than 1 wk of age seem to develop high peak levels of plasma triglycerides during fat infusion (25). These two findings are in agreement with the age-dependent increase of lipoprotein lipase activity found during parenteral nutrition (8) and suggest that lipoprotein lipase activity is not rate-limiting, except for the first days of parenteral nutrition.

Hepatic lipase activity has not previously been measured during parenteral nutrition. It was found that the activity of this enzyme remained unchanged during parenteral nutrition. However, after $3 \mathrm{wk}$ hepatic lipase activity decreased considerably in the two infants who were still under parenteral nutrition. The decrease may result either from cholestatic liver damage that both infants had or from the increase of age because hepatic lipase activity in infants is higher than in adults $(26,27)$.

In accordance with previous studies $(20,22,28,29)$, it was found that carnitine concentrations in serum and urine decreased considerably during parenteral nutrition. Decreased serum carnitine in preterm infants has been reported to be associated with impaired fatty acid oxidation $(22,29)$. Because free fatty acid and $\beta$-hydroxybutyric acid concentrations remained unchanged during parenteral nutrition, it is possible that low serum carnitine does not, in fact, reflect a shortage of carnitine in tissue. In agreement, the only infant autopsied had normal skeletal and heart muscle carnitine concentrations despite low serum and urinary levels. Thus, the rate-limiting role of carnitine remains unproven under the present circumstances. This conclusion is in agreement with the findings of Orzali et al. (23).

Acknowledgments. We thank Sirkka Runeberg, Paula Teräväinen, Hannele Hilden, and Hannu Kamppinen for their skillful technical assistance.

\section{REFERENCES}

1. Bartlett GR 1959 Phosphorus assays in column chromatography. J Biol Chem 234:466

2. Broquist HP, Borum PR 1982 Carnitine biosynthesis, nutritional implications. Adv Nutr Res 4:181

3. Cheung MC, Albers JJ 1977 The measurement of apolipoprotein A-I and A-II levels in men and women by immunoassay. $J$ Clin Invest $60: 43$

4. Cryer, A 1981 Tissue lipoprotein lipase activity and its action in lipoprotein metabolism. Int J Biochem 13:525

5. Curry MD, Gustafson A, Alaupovic P, McConathy WJ 1978 Electroimmunoassay, radioimmunoassay, and radial immunodiffusion assay evaluated for quantification of human apolipoprotein B. Clin Chem 24:280

6. Dhanireddy R, Hamosh M, Sivesubramanian KN, Chowdhry P, Scanlon JW, Hamosh P 1981 Postheparin lipolytic activity and intralipid clearance in very low-birth-weight infants. J Pediatr 98:617

7. Easton LB, Halata MS, Dweck HS 1982 Parenteral nutrition in newborn: a practical guide. Pediatr Clin North Am 29:1171

8. Forget PP, Fernandes J, Begemann PH 1975 Utilization of fat emulsion during parenteral nutrition in children. Acta Paediatr Scand 64:377

9. Fritz, IB, Yu KTN 1963 Long chain carnitine acyl transferase and the role of long chain fatty acid oxidation. J Lipid Res 4:279

10. Garfinkel AS, Nilsson-Ehle P, and Schotz MC 1976 Regulation of lipoprotein lipase induction by insulin. Biochim Biophys Acta 424:264

11. Goldberg IJ, Le NA, Paterniti JR Jr, Ginsberg HN 1982 Lipoprotein metabolism during acute inhibition of hepatic triglyceride lipase in the cynomolgus monkey. J Clin Invest 70:1184

12. Green PHR, and Glickman RM 1981 Intestinal lipoprotein metabolism. J Lipid Res 22:1153

13. Griffin E, Breckenridge WC, Kuksis A, Bryan MH, Angel A 1979 Appearance and characterization of lipoprotein $\mathrm{X}$ during continuous intralipid infusions in the neonates. $J$ Clin Invest 64:1703

14. Huttunen JK, Ehnholm C, Kinnunen PKJ, Nikkilä EA 1975 An immunochemical method for the selective measurement of two triglyceride lipases in human postheparin plasma. Clin Chim Acta 63:335

15. Jansen H, van Tol A, Hülsmann WC 1980 On the metabolic function of heparin-releasable liver lipase. Biochem Biophys Res Commun 92:53

16. Kuusi T, Kinnunen PKJ, Nikkilä EA 1979 Hepatic endothelial lipase antiserum influences rat plasma low and high density lipoproteins in vivo. FEBS Lett 104:384

17. McGarry JD, Foster DW 1976 An improved and simplified radioisotopic assay for the determination of free and esterified carnitine. J Lipid Res 17:277

18. Murase T, Itakura H 1981 Accumulation of intermediate density lipoprotein in plasma after intravenous administration of hepatic triglyceride lipase antibody in rats. Atherosclerosis 39:293

19. Nikkilä EA, Kuusi T, Taskinen MR 1982 Role of lipoprotein lipase and hepatic endothelial lipase in the metabolism of high density lipoproteins: a novel concept on cholesterol transport in HDL cycle. In: Carson A, Pernow B (eds) Metabolic Risk Factors in Ischemic Cardiovascular Disease. Raven Press, New York, pp 205-215

20. Novak M, Monkus E, Chung D, Buch M 1981 Carnitine in the perinatal metabolism of lipids. I. Relationship between maternal and fetal plasma levels of carnitine and acylcarnitines. Pediatrics 67:95

21. Olsen C 1971 An enzymatic fluorimetric micromethod for the determination of acetoacetate, 3-hydroxybutyrate, pyruvate and lactate. Clin Chem Acta 33:293

22. Orzali A, Donzelli F, Enzi G, Rubaltelli FF 1983 Effect of carnitine on lipid metabolism in the newborn. I. Carnitine supplementation during total parenteral nutrition in the first 48 hours of life. Biol Neonate 43:186

23. Orzali A, Maetzke G, Donzelli F, Rubaltelli FF 1984 Effect of carnitine on lipid metabolism in neonate. II. Carnitine addition to lipid infusion during prolonged total parenteral nutrition. J Pediatr 104:436

24. Penn D, Schmidt-Sommerfeld E, Pascu F 1981 Decreased tissue carnitine concentrations in newborn infants receiving total parenteral nutrition. $J$ Pediatr 98:976

25. Pereira GR, Fox WW, Stanley CA, Baker L, Schwartz JG 1980 Decreased oxygenation and hyperlipemia during intravenous fat emulsions in premature infants. Pediatrics 66:26

26. Rovamo L, Taskinen MR, Kuusi T, Nikkilä EA, Ehnholm C, Raivio KO 1984 Postheparin plasma lipase activities and plasma lipoproteins in newborn infants. Pediatr Res 18:642 
27. Rovamo L, Nikkilä EA, Taskinen MR, Raivio KO 1984 Postheparin plasma lipoprotein and hepatic lipase activities in preterm newborns. Pediatr Res 18:1104

28. Schiff D, Chan G, Seccombe D, Hahn P 1979 Plasma carnitine levels during intravenous feeding of the neonate. J Pediatr 95:1043

29. Schmidt-Sommerfeld E, Penn D, Wolf H 1983 Carnitine deficiency in premature infants receiving total parenteral nutrition: effect of L-carnitine supplementation. J Pediatr 102:931

30. Taskinen MR, Tulikoura I, Nikkilä EA, Ehnholm C 1981 Effect of parenteral hyperalimentation on serum lipoproteins and on lipoprotein lipase activity of adipose tissue and skeletal muscle. Eur $J$ Clin Invest 11:317

31. van Biervliet JP, Vinaimont N, Vercaemst R, Caster H, Rosseneu M 1981 Plasma apoprotein and lipid patterns in newborns: influence of nutritional factors. Acta Paediatr Scand 70:851
Vol. 19 , No. 3, 1985 Printed in U.S.A.

\title{
Newborn Sepsis following Antepartum Group B Streptococcal Maternal Infection in Rats
}

\author{
GARY J. NOEL, JOSE I. SANTOS, AND JOSEPH J. VITALE \\ Mallory Institute of Pathology, Boston City Hospital, Boston University School of Medicine, \\ Boston, Massachusetts 02118
}

\begin{abstract}
Group B streptococcus is an important pathogen in man and infection due to this bacteria is responsible for significant mortality and morbidity in neonates. An animal model of neonatal infection caused by group $B$ streptococcus that results from vertical transmission is described. Nine pregnant Sprague-Dawley rats received intraperitoneal inoculation of $10^{9}-10^{10}$ colony forming units of group B streptococcus on day 20 or 21 of gestation. Four of nine rats died following inoculation. A total of 51 pups was born to the surviving five mothers. Pups were sacrificed at 4- to 8-h intervals and cultures of blood, brain, liver, and spleen were obtained. Nineteen of 51 pups (37\%) had group B streptococcus isolated from blood or tissues within the first $48 \mathrm{~h}$ of life. Results suggest that antepartum systemic infection in rats can result in vertical transmission of disease. This animal model can be used to further study the mechanisms of transmission of group B streptococcus and the pathogenesis and treatment of neonatal sepsis caused by this pathogen. (Pediatr Res 19: 297-299, 1985)
\end{abstract}

\section{Abbreviations}

GBS, group B streptococcus

ip, intraperitoneal

CFU, colony forming units

Group B streptococcal infection occurs in two to three newborns per 1000 live births in the United States (1). Prophylactic intrapartum antibiotic regimens directed at interrupting transmission of GBS from mother to neonate has resulted in reduction of newborn colonization and infection (2-4). Difficulties in identifying women at risk for delivering infants who may develop group B streptococcal infections, however, have made indications for these regimens unclear.

Although an animal model for newborn group B streptococcal

Received August 24, 1984; accepted October 29, 1984.

Requests for reprints should be addressed to Jose I Santos, M.D., Mallory Institute of Pathology, 784 Massachusetts Avenue, Boston, MA 02118.

This research was supported in part by a grant from the Thrasher Foundation. sepsis in the rat has been established (5) and GBS surface colonization of pups born to mothers colonized with GBS has been demonstrated (6), a model in the rat that involves newborn sepsis resulting from maternal colonization of infection has not been described. The purpose of this study was to develop an animal model of vertical transmission of newborn sepsis following group B streptococcal challenge of mothers. A better understanding of the mechanisms of transmission of GBS and the pathogenesis of early-onset neonatal sepsis may help in our approach to new prophylactic and therapeutic regimens.

\section{MATERIALS AND METHODS}

Preparation of organisms. A human isolate of GBS type III further characterized as resistant to opsonization (7) was incubated in Todd-Hewitt broth (Difco Labs) at $37^{\circ} \mathrm{C}$ for $18 \mathrm{~h}$ and adjusted to $10^{8}-10^{9} \mathrm{CFU} / \mathrm{ml}$ in normal saline.

Animals. Pregnant outbred Sprague-Dawley rats (Charles River Labs) of 15-18 days gestation were obtained and housed in our animal quarters. On day 20 or 21 of gestation animals were given $2 \mathrm{ml}$ of GBS inoculum $\left(10^{9}-10^{10} \mathrm{CFU}\right)$ ip through a 25-gauge needle in the right upper quadrant of the abdomen. Care was taken not to inoculate viscera or uterus. Blood cultures obtained by incising the distal tail were taken at $2,24,48$, and $72 \mathrm{~h}$ following inoculation. Animals were closely observed and time of delivery was recorded. Soon after birth, and at regular intervals during the first $48 \mathrm{~h}$ of life, pups were sacrificed and cultures were obtained.

Isolation of GBS. Cultures were obtained from all dead adult females, stillborns, and sacrificed pups.

Blood for culture was obtained by aseptic intracardiac puncture with a 25 -gauge needle attached to a tuberculin syringe and inoculated onto blood agar plates which were incubated overnight at $37^{\circ} \mathrm{C}$.

Brain specimens were obtained by aseptic puncture of the cranium and aspiration with a 21-gauge needle attached to a tuberculin syringe. Brain tissue was inoculated onto blood agar plates and incubated.

Liver and spleen were aseptically removed from each animal upon opening the abdominal cavity. Care was taken not to incise the bowel or stomach and minimal bleeding was appreciated 